\title{
Entre agora e outrora: a escrita da história no cinema de Eduardo Coutinho
}

Claudia Cardoso Mesquita

Resumo: A cinematografia contemporânea de Eduardo Coutinho é marcada pela centralidade da entrevista como forma dramática e pelo registro do encontro presente entre o diretor e os sujeitos filmados. "Arte do presente", na expressão de Consuelo Lins (2002), esse cinema abriga, entretanto, um projeto mais raro, mas muito denso, de escrita da história. Propomos investigá-lo a partir do cotejo entre dois documentários separados por 20 anos - Cabra marcado para morrer (1984) e Peões (2004). Eles nos permitem, em suas semelhanças e diferenças, observar as iluminações recíprocas (entre passado e presente) ensejadas pela diacronia de Coutinho, que em nossa hipótese elabora "o presente como história" (YSHAGPOUR, 2000, p. 110).

Palavras-chave: Eduardo Coutinho; cinema documentário; história; Cabra marcado para morrer; Peões.

Abstract: Between now and yore: the history-writing in Eduardo Coutinho's cinema - Eduardo Coutinho's contemporary cinema is marked by the interview as a dramatic form, as well as the register of the ongoing encounter between the director and his interviewees. However, this "art of the present", as called by Consuelo Lins, implies a rarer, denser history-writing project. This paper explores this dimension of his work by comparing two films that are 20 years apart in their making: Twenty years later (1984) and Metalworkers (2004). Their similarities and differences allow us to note, between past and present, mutual insights that Coutinho's diachronic gesture brings about, which hypothetically constitutes "the present as history".

Keywords: Eduardo Coutinho; documentary; history; Twenty years later; Metalworkers.

\section{Apresentação: um cinema histórico "contra heróis"}

A cinematografia contemporânea de Eduardo Coutinho é marcada pela entrevista como forma dramática praticamente exclusiva (XAVIER, 2010, p. 66) e pelo registro dos "momentos únicos", como disse certa vez o cineasta, ${ }^{1}$ produzidos no encontro entre ele

1 Afirmação encontrada em entrevista a Maria Campaña Ramía (2012). 
e os sujeitos filmados. Muito próximo da tradição do cinema verdade, e precisamente chamado por Consuelo Lins (2002) de "arte do presente", este cinema abriga, entretanto, uma dimensão diacrônica e um movimento mais raro, mas de notável densidade: aquele caracterizado pela "preocupação em reconstruir o elo entre o passado e o presente de indivíduos ou comunidades", como escreveu Mateus Araújo Silva (2013a, p. 433). Em outras palavras, um projeto peculiar de escrita da história. Propomos investigar nesse projeto recorrências e variações, a partir do cotejo entre dois documentários históricos separados por 20 anos: Cabra marcado para morrer, obra-prima de 1984; e Peões, oitavo longa-metragem de Coutinho, de 2004. No percurso da análise, ensaiaremos aproximações entre esta cinematografia e a concepção de história defendida por Walter Benjamin em suas teses (BENJAMIN apud LÖWY, 2005). ${ }^{2}$ Caberia muito bem, para o cinema de Coutinho, a premissa benjaminiana de que "a relação entre hoje e ontem não é unilateral: em um processo eminentemente dialético, o presente ilumina o passado, e o passado iluminado torna-se uma força no presente", na síntese de Löwy (2005, p. 61). É precisamente essa dinâmica de mútua inteligibilidade (entre experiência atual e passado rememorado) que nos interessa observar nos dois filmes.

Antes, caberia notar, ainda com Mateus Araújo Silva, que a escrita da história, nas duas obras, diz respeito à articulação de passado e presente de "um grupo emblemático de trabalhadores brasileiros" (SILVA, 2013a, p. 434): camponeses que se organizaram politicamente em ligas, nos anos 1950 e 1960, no Nordeste do Brasil, em Cabra; e operários metalúrgicos que participaram das grandes greves da categoria, no final dos anos 1970, no Estado de São Paulo, em Peões. Em ambos, o passado corresponde a "momentos de luta organizada dos trabalhadores", e o presente, cerca de 20 anos depois, quando o filme é realizado ou retomado, a "momentos de dispersão dos seus sobreviventes" (SILVA, 2013a, p. 434), abordados, em cena, sobretudo individualmente.

O título em inglês do primeiro filme, Twenty years later, também valeria para Peões. Em ambos, o intervalo de 20 anos é fundamental, definidor de abordagem e narrativa. Meditar sobre a história, na obra de Coutinho, é articular um "agora" e um "outrora", 3 "reescrevendo" do presente as histórias de lutas populares passadas, mas não remotas (há sobreviventes para contá-las). Pois, na contramão do cientificismo - em todo caso, de projetos históricos empenhados em expurgar a memória -, os dois filmes apresentam essa história do ponto de vista de trabalhadores comuns, tecida por rememorações, balanços afetivos e versões pessoais dos acontecimentos passados. A multiplicação de histórias menores desafia qualquer pretensão de totalização. Resultam filmes "contra heróis", poderíamos dizer, retomando uma expressão lapidar do cineasta: ${ }^{4}$ dedicados às lembranças e pequenas resistências de pessoas que viveram os episódios do passado sem que sua participação fosse publicamente reconhecida, celebrada ou difundida.

2 Para uma ótima aproximação do cinema de Coutinho à teoria (não apenas da história) de Walter Benjamin, ver "Coutinho, leitor de Benjamin" (2011), de Laécio Ricardo de Aquino Rodrigues.

3 Emprestamos sugestão de Mateus Araújo Silva em seu artigo "Straub, Huillet e o ensaísmo dos outros" (2013b).

4 Como se vê no artigo "Coutinho: um filme 'contra heróis'". Entrevista a F. Molica, O Estado de S. Paulo, 02/12/1984. 
Isso nos remete, novamente, à perspectiva de Walter Benjamin. "Nada do que um dia aconteceu pode ser dado por perdido para a história" (BENJAMIN apud LÖWY, 2005, p. 54): o historiador materialista, na concepção benjaminiana, preza por recusar toda discriminação; cada vítima esquecida pela história oficial deveria ser rememorada. Essa atenção aos anônimos permite, como se nota no cinema de Coutinho, a reabertura do passado: a variante histórica que se cristalizou não é a única possível; os acontecimentos foram vividos e sofridos de inúmeras perspectivas, irredutíveis à narrativa histórica sintética e corrente.

Esses peculiares filmes históricos são também filmes sobre encontros, ou melhor, filmes baseados no encontro - os testemunhos sobre o passado sendo motivados pelo diálogo atual entre o diretor e seus personagens. Na montagem, a memória coletiva é tecida pela justaposição de rememorações individuais, nunca subsumidas a uma totalidade anterior; o desenho desta memória, feito assim de muitas camadas, depende ainda do trabalho peculiar com os arquivos. Pois, no documentário histórico de Coutinho, a ênfase no encontro presente não impede que outro traço forte provoque sua vizinhança com a tradição do ensaio histórico no cinema: a presença de imagens de arquivo (fotografias e trechos de filmes) e o consequente reforço da montagem como prática significante. Aliás, é a partir da retomada de ruínas e fragmentos de outras obras - imagens do filme inacabado, que Coutinho tentou realizar com camponeses nordestinos em 1964, em Cabra marcado para morrer; fotografias e trechos de filmes que retrataram as grandes greves do $A B C$ paulista, censuradas pela televisão, em Peões - que os dois filmes se colocam em curso.

O envolvimento pessoal do diretor e a natureza de sua mediação colocam diferenças expressivas entre os dois processos. Em Cabra marcado para morrer, Coutinho recusa as imagens de arquivos institucionais e se volta para o próprio acervo. O gesto fundamental do filme é a devolução das imagens realizadas no Engenho Galiléia (PE), em 1964, quando o diretor tentou filmar uma reconstituição da vida e da morte de João Pedro Teixeira, líder da Liga Camponesa de Sapé, assassinado em 1962. Os fragmentos do filme inacabado, cuja realização foi abortada pelo golpe civil-militar, são exibidos para os camponeses quando o diretor os reencontra, em 1981 e 1982, sendo mote para rememorações e narrativas. Em Peões, as imagens de arquivo, recolhidas de outras obras e contextos, são utilizadas na montagem para contextualização, mas, sobretudo, oferecem matéria para o dispositivo fílmico: ${ }^{5}$ as fotos e trechos de filmes que registraram a luta operária tornam-se elementos centrais no processo de pesquisa e busca por participantes anônimos das greves do $A B C$, potenciais entrevistados. Oferecidas ou exibidas aos filmados, são também

5 Aqui, dispositivo "remete à criação, pelo realizador, de um artifício ou protocolo produtor de situações a serem filmadas (...)" ou "à criação de uma 'maquinação', de uma lógica, de um pensamento, que institui condições, regras, limites, para que o filme aconteça" (LINS; MESQUITA, 2008, p. 56). 
elemento organizador da mise-en-scène e disparador da conversa atual, estimulando atos de fala e testemunhos. ${ }^{6}$ No processo, as fotografias são manuseadas, marcadas, comentadas, a apropriação do arquivo tematizada materialmente em cena.

Antes de desenvolvermos alguns desses pontos, gostaríamos de ressalvar: embora tragam gestos semelhantes, Cabra e Peões guardam muitas diferenças, que repercutem, em alguma medida, as peculiaridades dos contextos e movimentos políticos abordados em cada obra. Basta lembrar que a presença de Lula, nas imagens de arquivo e nas narrativas dos personagens, em Peões, fornece contraponto ao anonimato da maioria, e difere fundamentalmente da presença - também central - de João Pedro Teixeira em Cabra marcado para morrer (deste grande líder camponês, conta-nos o filme, restou apenas uma fotografia, morto). Uma análise do estatuto dos dois personagens já seria suficiente para opor a história de um líder popular vencido e assassinado (João Pedro) à história de um vencedor (Lula) - o que, por si só, registra mudanças expressivas na sociedade brasileira, em 40 anos de história. De todo modo, como em Cabra marcado para morrer , é a partir da ênfase nas rememorações de ex-grevistas "comuns" - e não das lideranças sindicais ou do próprio Lula - que se tece a memória coletiva em Peões, "um filme de câmara sobre um tema épico" (LINS, 2004), como Coutinho sintetizou tão bem. ${ }^{7}$

Talvez possamos resumir assim as complexas diferenças entre as duas lutas: o movimento camponês foi brutalmente interrompido e reprimido pela ditadura que se instalou no país após o golpe civil-militar de 1964; o movimento operário foi diretamente responsável pela redemocratização, aglutinando em torno das lideranças sindicais vários setores das lutas populares e democráticas, depois de 15 anos de ditadura. Um se situa na entrada, por assim dizer, e o outro na saída do período militar iniciado em 1964. Um movimento como que retoma ou responde ao apelo do outro, de modo que os dois filmes, postos lado a lado, não apenas sintetizam um percurso de lutas populares de fundamental importância na história contemporânea do Brasil - lutas que se deslocam, não por acaso, do campo para a cidade -, como indagam os seus desdobramentos futuros.

\section{A ênfase no presente}

Tanto Cabra como Peões valorizam o encontro presente, que deslancha a rememoração. Caberia perfeitamente para ambos a ideia benjaminiana de que na história que interessa, que confronta o historicismo, cúmplice dos vencedores -

6 Coutinho é mais um dos cineastas, como Rithy Pahn e André Labarthe, que apostam na confrontação direta dos arquivos da história às falas de testemunhas, como escreveu Anita Leandro (2015). Para a pesquisadora, "a mediação do documento põe a singularidade da fala à frente do discurso da história", permitindo ao cinema inscrever assim uma "poética do testemunho" em que a memória não aparece tão pautada pela história (RICOUER apud LEANDRO, 2015).

7 "A contradição é fazer um filme de câmara sobre um tema épico. Isto é, tema épico tratado como música de câmara. Tema épico: multidões, Lula presidente, luta de classes, o que seja, e a pessoa está na sua cozinha, na sua sala; e fala, cada um fazendo o seu pequeno solo" (COUTINHO apud LINS, 2004, p. 180). 
“o passado pode ser compreendido somente à luz do presente" (LÖWY, 2005, p. 71). Não se trata de reconstituir os acontecimentos vividos, como pretendia o filme interrompido em 1964. É o trabalho atual de rememoração que reabre o passado, dando uma nova chance ao que foi apagado, esquecido ou encoberto (pela história oficial), mas também indagando o presente, colocando-o em crise, exigindo elaboração - como se as esperanças envolvidas nas lutas passadas viessem nos indagar sobre os rumos que a história lhes deu ou tem Ihes dado.

Assim, uma das linhas fundamentais do dispositivo fílmico é o momento de filmagem. Peões foi realizado em 2002, quando Lula, presidente do sindicato dos metalúrgicos no momento das grandes greves, foi eleito pela primeira vez presidente do país, depois de três tentativas frustradas $(1989,1994,1998)$. Precisamente, entre o primeiro e o segundo turnos das eleições, quando já havia no ar um clima de euforia pela vitória iminente do ex-líder sindical. Em Cabra, não há um presente tão auspicioso e "vitorioso", mas sem dúvida trata-se de um momento oportuno e esperançoso: na retomada das filmagens, em 1981 e 1982, depois de quase duas décadas de ditadura e repressão aos movimentos sociais, os camponeses podem se reconectar - aparentemente sem perigo de vida - com o seu passado de militância política, e rememorar as violências sofridas durante o regime militar (no Brasil pós-Anistia e em vias de redemocratização). Cabe ao cineasta, para retomarmos Benjamin, fazer dessa ocasião um "tempo-de-agora" (LÖWY, 2005, p. 120) em que as falas abafadas possam enfim reverberar.

Notemos que a própria imagem da luta é submetida ao processo histórico o presente permite a abertura do passado e influi decisivamente em sua rememoração. Os grevistas foram derrotados em seu contexto imediato ${ }^{8}$ - mas, realizado mais de 20 anos depois, Peões registra o prazer em recordar e o orgulho de se incluir na história popular que agora triunfa institucionalmente. Mesmo que se possa reconhecer, com força de evidência, a dispersão, o isolamento e a solidão dos sobreviventes - a distância, em suma, que separa suas vidas, no presente, do trabalho nas fábricas e do movimento coletivo. Ou que não seja o velho PT, surgido no bojo das lutas sindicais, que esteja agora chegando ao poder, como no julgamento de Tê, personagem do filme. À diferença dos camponeses de Cabra, os ex-metalúrgicos de Peões participam de uma história consagrada, que se poderia mesmo dizer "vitoriosa", com a eleição iminente de Lula; mas tudo neles, da maneira como apanhados pelo filme, confessa a distância dos "melhores" tempos. ${ }^{9}$ Euforia ou disforia, triunfo ou perda? - oscilamos, confrontados com o seu presente.

Se o filme alcança essa ambiguidade, é porque privilegia associações e constelações disparadas do presente - não se limitando a uma construção fechada do passado nem endossando uma forma linear, progressiva, evolutiva. O mesmo para Cabra.

8 Os 41 dias de paralisação em 1980 não resultaram em ganhos salariais; houve pesada repressão policial e seguiram-se centenas de demissões.

9 Como escreveu Laécio Rodrigues, "demitidos das fábricas ou realocados em novas profissões, aposentados ou não, são abordados em seus domicílios, num contexto distante da projeção capitalizada por seus antigos líderes." (2011, p. 133). 
Como escreveu Bernardet (2013, p. 465), nada mais distante de sua estrutura do que o "espeto da cronologia" (com os fatos enfileirados e amarrados com "os barbantinhos das causas e efeitos"). Nos dois filmes, elabora-se "o presente como história": a cena atual faz apelo à rememoração e é por ela posta em perspectiva, ganhando historicidade e inscrevendo-se em um devir (YSHAGPOUR, 2000, p. 110). ${ }^{10}$ Em Cabra, por exemplo, mesmo que o reencontro entre cineasta e camponeses indique melhores tempos, as dificuldades que ainda cercam o trabalho de memória deixam ver um presente incerto (pois a ditadura ainda era uma realidade) e um futuro incógnito. ${ }^{11}$

\section{Contar a própria aventura}

No lugar de uma cronologia da história, privilegia-se, como fio narrativo, a exposição do percurso fílmico e da metodologia de abordagem, como se os dois filmes contassem "sua própria aventura", na expressão de Coutinho (1984). ${ }^{12}$ Assim procedendo, o diretor situa o alcance de sua representação de mundo - reescrever a história não implica rejeitar a exposição da perspectiva, o caráter circunstancial e mesmo subjetivo (no caso de Cabra) do enunciado. Não se trata da História em si mesma, em suma, mas do filme que a reescreve, erraticamente, provocando, em seu processo, encontros, reencontros, rememorações e associações.

É verdade que, em Cabra, o caráter processual é muito mais radical: o que o filme narra é efetivamente o seu fazer-se, a retomada (em novas bases) da filmagem, a busca incerta pelos atores. Tendo participado, como mediação para o movimento camponês, do processo político que não se limitou a registrar, a realização de Cabra foi interrompida pelo golpe civil-militar de 1964. Personagem da "aventura" como os camponeses, Coutinho volta ao Nordeste em 1981 para reencontrá-los. Neste retorno, interessa não apenas inscrever a história da vida e da morte do líder camponês João Pedro Teixeira, que o filme de 1964 buscara narrar - Coutinho precisa elaborar, junto aos camponeses, em cena, mas também na montagem, essa separação ou hiato de quase 20 anos, de modo a construir uma "ponte" (BERNARDET, 2013, p. 227), uma passagem entre tempos. O desafio de urdir, na montagem, a heterogeneidade da matéria fílmica, coincide assim com o desafio de narrar a história, como se o processo-filme correspondesse a um "cristal do acontecimento-total" (BENJAMIN, 2009, p. 503).

Não por acaso, Cabra foi considerado por Bernardet um "divisor de águas" no cinema brasileiro (2013, p. 09). Nele, o diretor passa a figurar como "mediação explícita entre

10 Emprestamos com liberdade expressão proposta por Yshagpour (2000) em sua discussão da história no cinema de Godard.

11 Emblemáticas do risco e da incerteza que ainda envolve a rememoração são as cenas com João Mariano, que se recusa a relembrar os tempos anteriores a 1964, quando participou do filme realizado no Engenho Galiléia; e o primeiro encontro com Elizabeth Teixeira, quando seu filho Abraão a constrange a agradecer ao então presidente militar João Batista Figueiredo.

12 Entrevista à Filme Cultura, edição 47: "O real sem aspas". 
o real e o espectador" (ibid., p. 233), assumindo, inclusive, uma das vozes narradoras em primeira pessoa. Em todo o seu cinema posterior, Coutinho se manteve em cena, mas não ocupando a posição que singulariza Cabra marcado para morrer: nele, como aqui defendemos, "contar a própria aventura" é a forma possível de abrigar a descontinuidade do processo de realização, e implica - necessariamente - uma elaboração da história. Já em Peões, não há este vínculo estreito entre a história do diretor, do filme que se faz, e dos trabalhadores retratados - não há narração em primeira pessoa, sequer há narração em off (alguns poucos letreiros fornecem informações sobre as greves no começo do filme). A busca via imagens não tem a mesma organicidade, nem o sentido de um retorno pessoal para concluir o que ficou em aberto.

No filme de 2004, diferentemente, as imagens recolhidas pelo diretor conformam um dispositivo, metodologia que dispara o processo-filme (e os sentidos): munida de um álbum com dezenas de fotos de jornais e de uma compilação de trechos de filmes que registraram as greves, a equipe de Coutinho provoca reconhecimentos - "uma cara num filme ou uma cara numa foto", como disse o diretor ${ }^{13}$. Coutinho não os conhece de antemão, e o filme busca sem saber quem busca. Mas notemos: não se procuram típicos ou célebres grevistas, e sim pessoas identificadas por outras nas imagens do passado. O método evita, assim, partir de um critério de representatividade, abrindo-se para o desconhecido e para a vida ordinária, mas também busca refazer precariamente laços ao evocar uma coletividade hoje ausente: só serão filmados aqueles cujos vestígios, impressos nos arquivos, são reconhecidos por ex-companheiros de categoria ou por lideranças do movimento grevista de 1979 e 1980. Notemos que o dispositivo vem ocupar, por assim dizer, a ausência de uma relação pessoal e de uma história comum entre diretor e personagens, deslocando para reconhecimentos (de ex-grevistas por ex-grevistas) a centralidade (inclusive simbólica) dos reencontros em Cabra marcado para morrer.

De todo modo, as diferenças entre tempos e perspectivas de vida também marcam a matéria histórica elaborada em Peões. Não é difícil notar que a maioria de seus entrevistados vive agora uma realidade bem diferente de outrora; a própria categoria (metalúrgicos) tem no presente outros contornos e dimensões. ${ }^{14}$ Ao planejar a "aventura" de Peões, Coutinho parece assumir esse esvaziamento: não se trata de realizar um épico histórico que reconstitua os grandes momentos do passado, mas de reconhecer a distância que separa o presente do tempo das greves. Por isso sua metodologia de busca por personagens corresponde a uma escolha historicamente significativa. As mudanças econômicas e sociais dispersaram vidas, antes reunidas em torno de condições de trabalho e de luta comuns; no presente, só um filme pode voltar a reuni-las, compondo na montagem uma delicada tessitura, feita também de brechas, nós, fios soltos,

13 Entrevista no encarte do DVD de Peões (2006).

14 Resultado de processos de reestruturação produtiva e do trabalho industrial, intensificados nos anos 1990 no Brasil. Progressivamente, a força de trabalho dos peões deixou de ser necessária a esta indústria de ponta, hoje ultramodernizada, como apontam alguns entrevistados no filme. 
buracos no tecido... Muitos rostos nas imagens restam incógnitos, e suas histórias, obscuras. De outros ex-metalúrgicos, identificados nas fotos, ninguém sabe o paradeiro. E de alguns o filme poderia fazer o epitáfio: "vocês têm que entrevistar esse cara, ele está morrendo, literalmente", ouvimos de um entrevistado.

\section{Arquivo e montagem}

O reconhecimento do hiato entre passado e presente - e a consciência da história como construção atual - também marca o projeto de Cabra marcado. Mais do que tematizar mudanças na realidade, o filme as abriga em sua forma, nas diferenças entre os registros que o compõem, em sua matéria híbrida e na pronunciada montagem final. Nesta, coexistem (e por vezes colidem) fragmentos da cinebiografia inacabada de João Pedro Teixeira, com encenações ficcionais, em preto e branco, 35 mm, câmera fixa, atuadas pelos próprios camponeses; e planos sequência coloridos, feitos em 16 mm, câmera na mão, som direto, o cineasta presente em cena, o filme retomado com estilo de reportagem. A opção por uma montagem heterogênea e fragmentária faz com que o próprio material filmado, suas diferentes cenas (realizadas em 1964 e em 1981/82) apareçam marcadas por distintas circunstâncias e possibilidades, inclusive tecnológicas, do cinema em sua "fricção com o mundo", para usar uma expressão de Jean-Louis Comolli (2001, p. 102).

Guardadas as diferenças, algo semelhante pode ser dito para Peões. No contraste com as imagens de arquivo, em que correspondiam a um rosto numa foto ou a um corpo apanhado em um movimento panorâmico de câmera, entre dezenas de outros, os personagens são filmados na privacidade de suas casas, quase sempre solitários, focalizados em primeiros planos. O contraste visual entre arquivos e tomadas no presente conduz uma argumentação tácita, que se reforça à medida que as sequências individuais se sucedem: o filme não apresenta apenas memórias das greves, mas elabora esta passagem (que é também cinematográfica) entre tempos - entre a experiência de participação em um movimento coletivo e a solidão em cena; entre o corpo agindo na rua e na massa e o fechamento na casa; entre o corpo a corpo com Lula (no palanque ou no sindicato) e o imaginário sobre o ex-líder sindical, hoje político de partido; entre o tempo de trabalhar e lutar, enfim, e o "tempo de lembrar"15.

Nos dois casos, as associações entre imagens alcançam outras reflexões, para além dos temas "maiores" a que cada filme oficialmente se dedica. Uma reflexão sobre o próprio cinema está no horizonte; mais precisamente, sobre sua relação intrínseca com o tempo, exposta a historicidade das formas. Em Cabra, quando Coutinho retorna ao Nordeste, em 1981, o copião do filme de 1964 é assumido como vestígio, resto da experiência interrompida, suas partes jamais restituídas ao todo significativo anteriormente pretendido

15 Ver "Peões: tempo de lembrar", (Mesquita; Guimarães, 2013). Como escreveu Mateus Araújo Silva, "a passagem da organização inicial à dispersão posterior dos trabalhadores ecoa no próprio cinema que acompanhou os dois momentos." (2013, p. 434). 
(mas nunca alcançado).Essa opção pelo fragmento se faz notar na maneira como o copião é exibido para os participantes das filmagens e trabalhado na montagem: com repetição de takes, claquetes visíveis, e obedecendo a múltiplos usos (sem a constância e a unidade formal que marcariam o projeto narrativo de 1964).

Tomemos um trecho. Depois de seu reconhecimento pelos companheiros, nas imagens projetadas pela equipe de cinema no Engenho Galiléia, vemos o reencontro de Coutinho com Cícero, um dos participantes do filme interrompido, em 1981 residente em Limeira (SP). No segmento, diferentes formas de abordar a realidade pelo cinema coexistem e contrastam (da reencenação à estilística da reportagem). Há contraste correspondente entre a experiência passada e o presente do personagem, tal como inscritas nas imagens (a experiência atomizada como migrante no sul, entrevistado individualmente pelo cineasta, contrasta com o engajamento na luta camponesa coletiva, registrada na encenação de que participou em 1964). Apesar dessa descontinuidade flagrante, a montagem do trecho trabalha de forma magistral a possibilidade de reconexão, de se fazer a ponte: quando, provocado por Coutinho, Cícero memoriza sua fala no filme original ("o charque está muito caro"), a cena de 1964 pode finalmente ser dublada, 20 anos depois do registro. É a sobreposição, na montagem, de fala atual (gravada em som direto) e imagens do passado (encenadas para serem posteriormente dubladas), que alcança esse efeito, sugerindo num átimo as diferenças expressivas entre os dois momentos, mas também indicando que o presente pode se sentir visado pelo passado e atender a seu apelo, segundo queria Benjamin (LÖWY, 2005): "para que o antes não fique sem futuro e o agora não fique sem passado", conforme sintetizou Bernardet (2013, p. 465-66).

De Peões, tomemos uma cena: o encontro comovente com João Chapéu, um dos ex-metalúrgicos entrevistados por Coutinho. A equipe de cinema traz imagens de arquivo, vistas pelo personagem na TV de casa. Desse modo, monta-se em cena o contraste entre agora e outrora. Nas imagens das greves, vemos João Chapéu em ação, fazendo piquete na porta da fábrica, um corpo entre outros corpos, a câmera se deslocando para dar conta de inserir em um só plano a movimentação grevista.

As diferenças colocadas pelas imagens do presente, realizadas 20 anos depois, não poderiam ser mais emblemáticas. Agora em espaço interno (dentro da casa de João Chapéu), a câmera fixa enquadra uma cadeira, na qual o personagem espera; pelas vozes fora de campo, percebemos que mais alguém hesita em entrar em cena. É a esposa de João Chapéu, que assim justifica sua escolha por não "aparecer" no filme: "Não quero me envolver". É por essa recusa que Coutinho parece se interessar especialmente, como se ela sintetizasse melhor o momento atual do que as reafirmações da luta por João Chapéu. ${ }^{16}$ Tanto é assim que o diretor começa a entrevista perguntando pela história do namoro do casal (como quem deseja se aproximar da esposa).

16 Para o personagem, a participação na categoria, em 2002 tão remota, ainda marcava e era motivo de orgulho: "não sou um verdadeiro taxista", afirma no filme João Chapéu. Demitido após a greve de 1980, em 2002 ele era taxista há mais tempo do que fora metalúrgico. 
Então, vejamos: no trecho de Cabra, a montagem opera uma junção, um corpo ganha uma voz, um plano se completa (depois de 17 anos); em Peões, a cena atual expõe sua incompletude, uma voz fora-de-campo permanece sem corpo, a solidão de João Chapéu significa o presente.

\section{Obra em processo, processo como obra - considerações finais}

Cabra e Peões são filmes em que, do presente, duas décadas depois, trabalhadores rememoram lutas passadas. O intervalo de 20 anos, fundamento do dispositivo fílmico, se impõe como necessidade histórica (em Cabra) e produz historicidade (nos dois casos): não se trata apenas de rememorar o passado, mas de colocar tacitamente o presente em perspectiva, indagando os desdobramentos daquelas lutas. O hiato entre tempos, produtor de contrastes, motiva elaborações, pontes, passagens: abrigadas nas imagens, as diferenças entre "outrora" e "agora" são trabalhadas sob a forma de associações e contrastes visuais, a história não apenas como motivo dos testemunhos, mas inscrita na matéria fílmica que a montagem organiza, com resultados singulares em cada filme.

Assim, é do jogo de iluminações recíprocas (entre passado e presente) que cada filme retira a força crítica de seu trabalho histórico - é também neste cruzamento (o que o presente da rememoração aporta ao passado rememorado e vice-versa) que devemos buscar, enfim, diferenciá-los. Enquanto Cabra abriga um processo histórico (refratando, a partir de sua matéria fílmica descontínua, 20 anos de história), Peões cria um dispositivo para internalizá-la. ${ }^{17}$ No primeiro caso, reencontros movidos pela devolução das imagens provocam rememorações, balanços, reconexões (mas também fissuras) com a militância pré-64. No segundo, reconhecimentos tecem a precária (e aleatória) rede de potenciais entrevistados, o filme como local de reunião possível (de uma categoria colapsada).

Em Cabra marcado para morrer, rememorar é produzir uma contra-história, e ainda resgatar estrategicamente uma identidade política abafada, de modo a municiar o presente, abrindo-o a um outro porvir. "Metaforicamente, a heroína enfim reconhecida e o filme enfim realizado restabelecem a continuidade com o movimento popular anterior a 1964, e desmentem a eternidade da ditadura, que não será o capítulo final", escreveu Roberto Schwarz em seu texto antológico (2013, p. 460). Rememorar para fazer com que algo do projeto político pré-64 sobreviva e volte a animar o presente. Pois para reinventá-lo, diria Jeanne-Marie Gagnebin (2006), esboçando uma outra história, é mister que o passado seja transmitido.

Em Peões, rememorar não deixa de ser celebrar a vitória institucional de uma liderança popular, como que distribuindo seus louros com protagonistas anônimos da história. Mas também reconhecer, já que se rememora no presente, a distância dos tempos de fábrica e sindicato (em momento pós-industrial e de política partidária). No primeiro caso, é preciso estabelecer a ponte, criando continuidade sobre a drástica ruptura

17 Faço aqui referência ao debate "Obra em processo, ou processo como obra?" (2011). 
(o golpe civil-militar e a repressão violenta aos movimentos sociais); no segundo, a escrita da história sugere descompassos, separações, rasuras e rupturas (onde uma abordagem mais triunfalista veria apenas continuidade, quiçá progressão teleológica: entre as greves e a eleição de Lula para presidente). Atomizados, dispersos, isolados, não são mais metalúrgicos (em sua maioria) aqueles que, em Peões, rememoram e comemoram esta vitória. Celebração ou réquiem para a classe operária?

Cláudia Cardoso Mesquita é professora do Curso de Comunicação Social e do Programa de Pós-Graduação em Comunicação Social da UFMG. É doutora em Ciências da Comunicação pela ECA-USP e integra o grupo de pesquisa Poéticas da Experiência.

claudmesq@gmail.com

\section{Referências}

BENJAMIN, Walter. Passagens. Belo Horizonte: UFMG; São Paulo: Imprensa Oficial do Estado de São Paulo, 2009.

BERNARDET, Jean-Claude. Vitória sobre a lata de lixo da história. In: OHATA, Milton (Org.). Eduardo Coutinho. São Paulo: CosacNaify, 2013.

COMOLLI, Jean-Louis. Sob o risco do real. In: CATÁLOGO do forumdoc.bh 2001. Belo Horizonte: Associação Filmes de Quintal, 2001.

COUTINHO, Eduardo. Coutinho: um filme 'contra heróis'. O Estado de S. Paulo, São Paulo, 2 dez. de 1984, p. 2. Entrevista concedida a F. Molica.

O real sem aspas. Entrevista concedida a Ana Maria Galano, Aspásia Camargo, Zuenir Ventura e Claudio Bojunga, Filme Cultura, Rio de Janeiro, ed. 47, 1984.

Entrevista no encarte de Peões. VideoFilmes, 2006. DVD.

GAGNEBIN, Jeanne-Marie. Memória, história, testemunho. In: GAGNEBIN, J.M. Lembrar escrever esquecer. São Paulo: Editora 34, 2006.

LEANDRO, Anita. Montagem e história: uma arqueologia das imagens da repressão. In: ENCONTRO DA ASSOCIAÇÃO NACIONAL DOS PROGRAMAS DE PÓS-GRADUAÇÃO EM COMUNICAÇÃO, 24, Brasília, 2015. Anais da COMPÓS, Brasília, Disponível em < http://www.compos.org.br/biblioteca/ artigo_com-autoria_compos-2015-3443f24d-7f10-4aaf-857c-1441b53a7204_2837.pdf >. Acessado em 20/7/2015.

LINS, Consuelo. O cinema de Eduardo Coutinho: uma arte do presente. CADERNOS de Antropologia e Imagem, Rio de Janeiro, v. 15, n. 1, p. 61-81, 2002.

O documentário de Eduardo Coutinho: televisão, cinema e vídeo. Rio de Janeiro: Jorge Zahar, 2004. 
.; MESQUITA, Cláudia. Filmar o real: sobre o documentário brasileiro contemporâneo. Rio de Janeiro: Jorge Zahar, 2008.

LÖWY, Michael. Walter Benjamin: aviso de incêndio. Uma leitura das teses "Sobre o conceito de história". São Paulo: Boitempo, 2005.

MESQUITA, Cláudia; GUIMARÃES, Victor. Peões: tempo de lembrar. In: OHATA, Milton (Org.). Eduardo Coutinho. São Paulo: Cosac Naify, 2013.

Obra em processo ou processo como obra?... Rio de Janeiro: CCBB, 05 maio 2011. Não publicado.

RAMíA, Maria Campaña. No quiero saber cómo es el mundo, sino cómo está : una conversación con Eduardo Coutinho. In: RAMÍA, María Campaña; MESQUITA, Cláudia (Orgs.). El otro cine de Eduardo Coutinho. Quito: Corporación Cinememoria; Embaixada do Brasil, 2012.

RODRIGUES, Laécio Ricardo de Aquino. Coutinho, leitor de Benjamin. Devires, Belo Horizonte, v. 8, n. 2, p. 118-137, jul./dez. 2011.

SCHWARZ, Roberto. O fio da meada. In: OHATA, Milton (Org.). Eduardo Coutinho. São Paulo: CosacNaify, 2013.

SILVA, Mateus Araújo. Eduardo Coutinho, Pierre Perrault e as prosódias do mundo. In: OHATA, Milton (Org.). Eduardo Coutinho. São Paulo: CosacNaify, 2013, p. 432-439. [2013a].

SILVA, Mateus Araújo. "Straub, Huillet e o ensaísmo dos outros". Devires, v. 10, n. 1, p. 108-137, jan./ jun. [2013b].

XAVIER, Ismail. Indagações em torno de Eduardo Coutinho e seu diálogo com a tradição moderna. In: MIGLIORIN, Cezar (Org.). Ensaios no real: o documentário brasileiro hoje. Rio de Janeiro: Azougue, 2010.

YSHAGPOUR, Youssef. J-L G cinéaste de la vie moderne: le poétique dans I’historique. In: GODARD, J-L.; YSHAGPOUR, Y. Arquéologie du cinéma et mémoire du siècle (dialogue). Tours: Farrago, 2000. 